\title{
Synthesis of a novel imidazolium-based ionically-tagged ruthenium complex
}

\author{
Júlia R. Diniz' ${ }^{1}$, Karlla M. C. Ferreira ${ }^{1}$, Paulo A. Z. Suarez ${ }^{1}$, Brenno A. D. Neto ${ }^{1}$ \\ ${ }^{1}$ Laboratory of Medicinal and Technological Chemistry (LaQuiMeT), Chemistry Institute, University of \\ Brasilia \\ *jugirossi@hotmail.com
}

Keywords: ruthenium, ionically-tagged catalysts, ionic liquids.

\section{INTRODUCTION}

In the mid of 80 's, studies emerged to replace the use of phosgene in the synthesis of carbamates by carbon dioxide, due to its lower toxicity. ${ }^{1}$ The idea proved successful when Dixneuf and coworkers took advantage of the equilibrium between an amine, carbon dioxide and the corresponding ammonium carbamate and the fact that ruthenium is able to activate alkynes. ${ }^{2}$

Considering this, we describe the synthesis of a novel imidazolium-based ionically-tagged ruthenium complex to be tested in some catalytic reactions aiming to tune some advantages of an imidazolium moiety in the complex structure.

\section{RESULTS AND DISCUSSION}

The ruthenium complex was synthesized as described in Scheme 1.
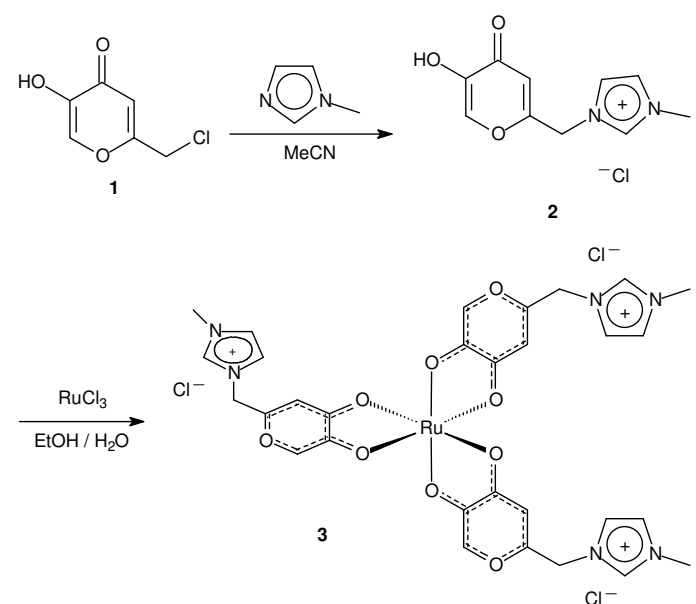

Scheme 1. Synthesis of the ionically-tagged ruthenium complex.

Complex 3 was fully characterized and its elemental analysis, IV, ${ }^{1} \mathrm{H}$ and ${ }^{13} \mathrm{C}$ NMR (Figure 1 ) were acquired.

${ }^{13} \mathrm{C}$ NMR of the ligand and of the complex gave distinctive chemical shifts, confirming the complexation to the metal center. ${ }^{13} \mathrm{C}$ NMR $\left(\mathrm{D}_{2} \mathrm{O}\right) \delta$ (ppm) for the ligand is 178.7, 162.9, 147.6, 144.8, $139.6,126.6,125.2,116.1,51.9,38.5$ and for the complex is $176.5,160.3,145.1,142.3,137.0,124.1$, 122.7, 113.6, 49.3, 36.0.
There was a change of about 2-3 ppm for all signals in the chemical shifts.
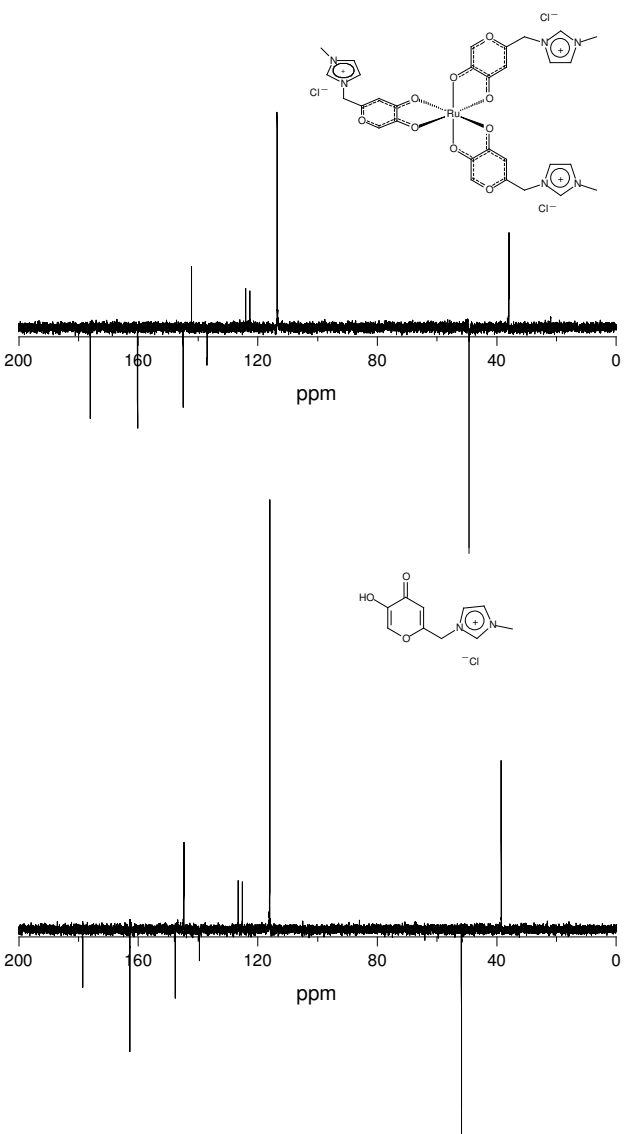

Figure $1 .{ }^{13} \mathrm{C}-\mathrm{NMR}$ of the complex (3) and of the ligand (2), respectively.

\section{CONCLUSION}

The ionically-tagged ruthenium complex was successfully synthesized in high yields.

\section{ACKNOWLEDGEMENTS}

To CNPq, FAPDF and CAPES for financial support.

\section{REFERENCES}

1,2 Mahé, R.; Sasaki, Y.; Bruneau, C.; Dixneuf, P. H. J. Org. Chem. 1989, 54,1518 . 